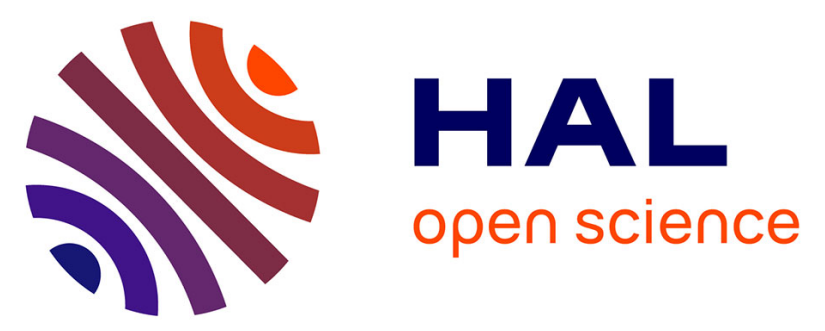

\title{
2,6-Di(pyrazol-3-yl)pyridine as meridional capping ligand: Synthesis, characterization and crystal structure of the first corresponding hexanuclear iron(III) complex
}

Daniel Plaul, Eike Spielberg, Winfried Plass

\section{- To cite this version:}

Daniel Plaul, Eike Spielberg, Winfried Plass. 2,6-Di(pyrazol-3-yl)pyridine as meridional capping ligand: Synthesis, characterization and crystal structure of the first corresponding hexanuclear iron(III) complex. Journal of Inorganic and General Chemistry / Zeitschrift für anorganische und allgemeine Chemie, 2010, 636 (7), pp.1268. 10.1002/zaac.201000075 . hal-00552459

\section{HAL Id: hal-00552459 \\ https://hal.science/hal-00552459}

Submitted on 6 Jan 2011

HAL is a multi-disciplinary open access archive for the deposit and dissemination of scientific research documents, whether they are published or not. The documents may come from teaching and research institutions in France or abroad, or from public or private research centers.
L'archive ouverte pluridisciplinaire HAL, est destinée au dépôt et à la diffusion de documents scientifiques de niveau recherche, publiés ou non, émanant des établissements d'enseignement et de recherche français ou étrangers, des laboratoires publics ou privés. 
2,6-Di(pyrazol-3-yl)pyridine as meridional capping ligand: Synthesis, characterization and crystal structure of the first corresponding hexanuclear iron(III) complex

\begin{tabular}{|c|c|}
\hline Journal: & Zeitschrift für Anorganische und Allgemeine Chemie \\
\hline Manuscript ID: & zaac.201000075.R1 \\
\hline Wiley - Manuscript type: & Article \\
\hline $\begin{array}{r}\text { Date Submitted by the } \\
\text { Author: }\end{array}$ & 18-Mar-2010 \\
\hline Complete List of Authors: & $\begin{array}{l}\text { Plaul, Daniel } \\
\text { Spielberg, Eike } \\
\text { Plass, Winfried; Friedrich-Schiller-Universitaet Jena, Institut für } \\
\text { Anorganische und Analytische Chemie }\end{array}$ \\
\hline Keywords: & $\begin{array}{l}\text { Iron, Hexanuclear complex, Magnetic properties, Pyrazole-based } \\
\text { ligand, X-ray diffraction }\end{array}$ \\
\hline
\end{tabular}

\section{s) ScholarONE" \\ Manuscript Central}




\title{
2,6-Di(pyrazol-3-yl)pyridine as meridional capping ligand: Synthesis, characterization and crystal structure of the first corresponding hexanuclear iron(III) complex
}

\author{
Daniel Plaul, ${ }^{[a]}$ Eike T. Spielberg, ${ }^{[a]}$ and Winfried Plass ${ }^{*[a]}$ \\ Dedicated to Professor Gerd Becker on the occasion of his 70th birthday
}

\begin{abstract}
Based on the 2,6-di(pyrazol-3-yl)pyridine ligand ( $\mathrm{H}_{2} \mathrm{bpp}$ ) the hexanuclear iron(III) complex $\left[\mathrm{Fe}_{6}(\mathrm{bpp})_{4}\left(\mu_{3}-\mathrm{O}\right)_{2}(\mu-\mathrm{OMe})_{3}(\mu-\mathrm{OH}) \mathrm{Cl}_{2}\right](\mathbf{1})$ has been synthesized. The reaction with iron(II) chloride and additional pyridine leads to the exclusive formation of the complex through self-assembly process. Six octahedrally coordinated iron centers are linked through the pyrazolido groups of four $\mathrm{H}_{2}$ bpp ligands. These are further linked through bridging hydroxido, methoxido, and oxido groups. The complex has been characterized by IR spectroscopy, ESI mass spectrometry, elemental analysis and X-ray crystallography. Temperature-dependent magnetic measurements indicate strong antiferromagnetic exchange interaction between the high-spin iron(III) centers within the complex leading to an $S=0$ spin ground state. As a result of the two $\mathrm{Fe}_{3}\left(\mu_{3}-\mathrm{O}\right)$ fragments two frustrated exchange pathways are present. In addition the properties of $\mathrm{H}_{2}$ bpp as a potential capping ligand for the synthesis of heteroleptic trinuclear complexes based on the triaminoguanidine core is investigated.
\end{abstract}

Keywords: Iron; Hexanuclear complex; Magnetic properties; Pyrazole-based ligand; X-ray diffraction.

* Prof. Dr. W. Plass

Fax: +49 (0)3641 948132

E-Mail: sekr.plass@uni-jena.de

[a] Institut für Anorganische und Analytische Chemie

Friedrich-Schiller-Universität Jena

Carl-Zeiss-Promenade 10

07745 Jena, Germany 


\section{Introduction}

The 2,2':6',2"-Terpyridine (terpy) and its derivatives are widely used ligands in coordination chemistry [1,2]. Terpy can bind to both low- and high-oxidation state metal ions, almost always in a tridentate fashion [1,3]. While terpy ligands have been intensely studied due to their commercial accessibility as well as straightforward synthetic access, the analogues pyrazolyl ligands have been less investigated [4]. Especially the 2,6-di(pyrazol-3-yl)pyridine ligand $\left(\mathrm{H}_{2} \mathrm{bpp}\right)$ shown in Scheme 1 has only scarcely been utilized.

This ligand is known to form mononuclear homoleptic iron(II) complexes of the general formula $\left[\mathrm{Fe}\left(\mathrm{H}_{2} \mathrm{bpp}\right)_{2}\right] \mathrm{X}_{2}$ which are stable in air and undergo temperature induced spin crossover [5-10]. While the temperature of these transitions vary considerably, it can be generalized that hydration of the compounds tends to favor the low-spin state of the iron center. Besides only a few cobalt(II), nickel(II) and copper(II) complexes as well as the corresponding lanthanide complexes with three ligand molecules of the general formula $\left[\mathrm{Ln}\left(\mathrm{H}_{2} \mathrm{bpp}\right)_{3}\right]\left[\mathrm{PF}_{6}\right]_{3}$ have been described in literature $[9,11-13]$. All these complexes are found to be exclusively mononuclear, independent of the central metal ion. Although the ligand system offers with the second nitrogen atom of the pyrazolyl moieties two additional potential donor groups, no covalently linked dinuclear or oligonuclear complexes of divalent metal ions have been reported until now. Nevertheless, deprotonation of the pyrazole $\mathrm{NH}$ groups should provide an access to higher nuclearity aggregates. This has been proven for derivatives with the methyl and phenyl substitutents at the 5-position of the pyrazole rings of the ligand system leading to octanuclear copper(I) complexes [14]. The $\mathrm{H}_{2}$ bpp ligand system can be considered as ideal candidate for meridional capping of octahedral complex fragments, which in addition might be able to introduce spin-crossover properties. A prototypical case for which capping has been utilized with similar tridentate ligands is the trinuclear core fragment based on the tritopic triaminoguanidine ligand [15].

Herein we report on attempts to synthesize appropriate heteroleptic trinuclear complexes with $\mathrm{H}_{2}$ bpp as capping ligand. This finally resulted in the synthesis of the first hexanuclear iron(III) complex $\left[\mathrm{Fe}_{6}(\mathrm{bpp})_{4}\left(\mu_{3}-\mathrm{O}\right)_{2}(\mu-\mathrm{OMe})_{3}(\mu-\mathrm{OH}) \mathrm{Cl}_{2}\right]$ (1) with the parent bispyrazolyl-pyridine ligand system.

\section{Results and Discussion}

\section{Synthesis and Characterization}

The ligand $\mathrm{H}_{2}$ bpp was obtained in a two step synthesis through condensation of 2,6diacetylpyridine with $N, N$-dimethylformamide diethyl acetal and subsequent formation of the heterocycles with hydrazine in nearly quantitative yield [16]. With this tridentate capping ligand we attempted the synthesis of heteroleptic trinuclear iron complexes based on the tritopic triaminoguanidine core fragment represented in Scheme 2. We have previously employed this tritopic core fragment in the synthesis of trinuclear octahedral nickel(II) complexes [17] and as building block for the generation of copper(II) coordination polymers $[18,19]$.

Iron(II) chloride has generally been used as starting material in all experiments, which is added to a solution of the triaminoguanidine core ligand containing the appropriate base to account for its deprotonation. The solution immediately turns reddish or greenish indicating initial coordination of the iron center, although the actual color depends on the solvent (DMF or pyridine) and whether aerobic or anaerobic conditions are employed. 
If the reaction is run under anaerobic conditions in DMF as solvent and triethylamine as base, after addition of the $\mathrm{H}_{2}$ bpp ligand the homoleptic complex cation $\left[\mathrm{Fe}\left(\mathrm{H}_{2} \mathrm{bpp}\right)_{2}\right]^{2+}$ is obtained from the initially red solution, which has been identified by comparison of the spectroscopic data with an authentic sample [5]. A similar phenomenon is observed when the reaction is run in pyridine as solvent, which also acts as the needed base. Under these conditions from the red solution $\left[\mathrm{Fe}(\mathrm{py}){ }_{4} \mathrm{Cl}_{2}\right][20,21]$ is obtained as the sole iron species. Both cases are indicative for a stabilization of the homoleptic and mononuclear species with respect to the heteroleptic trinuclear arrangement and consequently results in the extraction of the metal ion from the pre-built trinuclear core.

Under aerobic conditions in DMF with triethylamine as base the initial reaction solution immediately turns deep green and within minutes the precipitation of dark colored unidentified products is observed. This cannot be prevented by the addition of the potential capping ligand $\mathrm{H}_{2}$ bpp, even if this co-ligand is added without any delay in the reaction sequence. On the other hand, when pyridine is used as solvent the initially red reaction solution intensifies its color upon the addition of the $\mathrm{H}_{2}$ bpp ligand. From the final reaction solution a red crystalline material could be isolated in high yield, which does not contain the triaminoguanidine ligand. This again leads to the extraction of the metal ion from the core ligand fragment. The isolated compound could be characterized as the hexanuclear iron(III) complex $\left[\mathrm{Fe}_{6}(\mathrm{bpp})_{4}\left(\mu_{3}-\mathrm{O}\right)_{2}(\mu-\mathrm{OMe})_{3}(\mu-\mathrm{OH}) \mathrm{Cl}_{2}\right](\mathbf{1})$ with a deprotonated bispyrazolylpyridine ligand system.

The hexanuclear iron(III) complex 1 can also be deliberately synthesized in absence of the triaminoguanidine ligand. In this case iron(II) chloride is dissolved in a pyridine/methanol (1:1) mixture and the $\mathrm{H}_{2}$ bpp ligand is added to this solution. This sequence is chosen in order to prevent the formation of the homoleptic mononuclear iron(II) complex. The pyridine acts both as solvent and base. During complexation the iron(II) ions are oxidized. The deprotonation of the two acidic pyrazole protons allows further aggregation and leads to the formation of the hexanuclear complex $\left[\mathrm{Fe}_{6}(\mathrm{bpp})_{4}\left(\mu_{3}-\mathrm{O}\right)_{2}(\mu-\mathrm{OMe})_{3}(\mu-\mathrm{OH}) \mathrm{Cl}_{2}\right]$ through self-assembly process. Complex 1 has been characterized by IR spectroscopy, mass spectrometry, elemental analysis, and X-ray crystallography.

The IR spectra of complex 1 show several characteristic features supporting the given composition and structure. At first the NH stretching vibration in the free ligand observed at about $3200 \mathrm{~cm}^{-1}$ is absent in the spectra of the isolated compound, which is consistent with the full deprotonation of the pyrazolyl groups in the ligand. This clearly indicated the absence of the homoleptic mononuclear iron(II) complex cation $\left[\mathrm{Fe}\left(\mathrm{H}_{2} \mathrm{bpp}\right)_{2}\right]^{2+}$ as potential byproduct in this reaction. Characteristic bands are observed at 2918 and $2814 \mathrm{~cm}^{-1}$, which can be assigned to the asymmetric and symmetric stretching vibration of the methyl groups of the bridging methoxido ligands. The band of the $\mathrm{OH}$ stretching vibration of the bridging hydroxido group is observed at $3435 \mathrm{~cm}^{-1}$. In addition also a very strong and broad band is observed at $493 \mathrm{~cm}^{-1}$ due to the iron-chloride stretching vibration.

In the positive ion electrospray (ESI) mass spectrum the base peak is observed at an $\mathrm{m} / \mathrm{z}$ value of 1349 which can be assigned to the hexanuclear iron complex which lost one of the coordinated chloride ions. Moreover, an additional intense signal is observed at $\mathrm{m} / \mathrm{z}=1313$ due to the loss of the second coordinated chloride ion accompanied by a proton.

\section{Description of the structure}

The hexanuclear iron(III) complex 1 crystallizes in the monoclinic space group $P 2_{1}$. The molecular structure as well as the heteroatom labeling scheme of the complex molecule is 
depicted in Figure 1. The structure of the central $\mathrm{Fe}_{6}$ core unit is enlarged in Figure 2. Selected bond lengths and angles are listed in Table 1.

Four iron centers (Fe1, $\mathrm{Fe} 2, \mathrm{Fe} 3$, and $\mathrm{Fe} 4)$ are coordinated by the deprotonated meridional capping ligand $\mathrm{bpp}^{2-}$ in its terpy-like coordination pocket. The pyrazolido fragments are coordinated to two additional iron centers ( $\mathrm{Fe} 5$ and $\mathrm{Fe} 6$ ) leading to a paddle-wheel structure with an additional chloride ion coordinated at both iron centers forming the corresponding axle. The four planar $\{\mathrm{Fe}(\mathrm{III}) \mathrm{bpp}\}^{+}$subunits in the paddle wheel are arranged perpendicular to each other and further linked by one $\mu-\mathrm{OH}$ and three $\mu$-OMe bridging groups. In addition both iron centers (Fe5 and Fe6) at the axle are further linked to two different $\{\mathrm{Fe}(\mathrm{III}) \mathrm{bpp}\}^{+}$ subunits of the paddle wheel forming two $\mathrm{Fe}_{3}\left(\mu_{3}-\mathrm{O}\right)$ fragments. The sixth coordination site of both iron(III) ions Fe5 and Fe6 are occupied by a chloride ion resulting in a neutral hexanuclear complex.

For all iron(III) ions a distorted octahedral coordination environment is observed with a $\mathrm{N}_{3} \mathrm{O}_{3}$ donor set for the iron centers $\mathrm{Fe} 1, \mathrm{Fe} 2, \mathrm{Fe} 3$, and $\mathrm{Fe} 4$, whereas a $\mathrm{N}_{4} \mathrm{OCl}$ donor set is found for Fe5 and Fe6. For the latter two iron centers Fe5 and Fe6 this distortion is rather small, whereas for the four iron centers of the $\{\mathrm{Fe}(\mathrm{bpp})\}^{+}$subunits a severe distortion is observed as indicated by the relevant trans bridging angles (see Table 1). The small $\mathrm{N}-\mathrm{Fe}-\mathrm{N}$ trans angles of about $144^{\circ}$ within the subunits are determined by rigid meridional capping ligand and the size of the large high-spin iron(III) ion. The formation of the $\mathrm{Fe}_{3} \mathrm{O}$ fragments is related to the second set of small trans angles, as indicated by the $\mathrm{O}-\mathrm{Fe}-\mathrm{N}$ bond angles of about $154^{\circ}$ between the pyridine donor of the bpp ${ }^{2-}$ ligand and the $\mu_{3}$-bridging oxygen atoms (O1 and $\mathrm{O} 2)$.

These distortions lead to dissimilar $\mathrm{Fe}-\mathrm{N}$ bond lengths of the two pyrazolido moieties of the ligand, depending on whether $(206 \mathrm{pm})$ or not $(218 \mathrm{pm})$ they are involved in the bridging of the $\mathrm{Fe}_{3} \mathrm{O}$ fragments. This might be attributed to considerable differences regarding the structural trans effect of the relevant donors. The $\mathrm{Fe}-\mathrm{N}$ bond lengths of the four pyridine nitrogen donors are with about $220 \mathrm{pm}$ well within the expected range and somewhat longer than corresponding distances found for the pyrazolido nitrogen donors. The $\mathrm{Fe}-\mathrm{O}$ bond lengths within the $\mathrm{Fe}_{3} \mathrm{O}$ fragments are found at about $201 \mathrm{pm}$ for the iron centers of the $\mathrm{Fe}(\mathrm{bpp})^{+}$subunits, whereas considerably shorter distances are found for Fe5 and Fe6 with about $193 \mathrm{pm}$. The two remaining coordination sites at the iron centers Fe1, Fe2, Fe3, and Fe4 are occupied by bridging oxygen atoms of methoxido and hydroxido groups with $\mathrm{Fe}-\mathrm{O}$ distances of about $198 \mathrm{pm}$ and $194 \mathrm{pm}$, respectively. Besides the $\mu_{3}$-bridging oxygen atoms (O1 and $\mathrm{O} 2$ ) the iron centers $\mathrm{Fe} 5$ and $\mathrm{Fe} 6$ are additionally coordinated by four nitrogen atoms of the pyrazolido moieties at distances ranging between $210 \mathrm{pm}$ and $213 \mathrm{pm}$. The octahedral coordination environment of both iron centers is completed by a chloride ion coordinated at a distances of about $241 \mathrm{pm}$. The bond lengths for all iron centers are in the usually observed range typical for iron(III) high-spin complexes [22].

The iron centers within the complex are linked through three different types of bridges. Besides the linkages with $\mu-\mathrm{OMe}, \mu-\mathrm{OH}$, and $\mu_{3}-\mathrm{O}$ groups the iron centers are further linked through $\mathrm{N}-\mathrm{N}$ diazine bridges of the pyrazolido moieties of the bpp ${ }^{2-}$ ligand (see Figure 2). The torsion angles of the diazine bridges are very similar and in the range between 170 and $180^{\circ}$ due to the planarity of the $\{\mathrm{Fe}(\mathrm{bpp})\}^{+}$subunits (see Table 2). The bond angles at the bridging oxygen atoms are summarized in Table 3 . The $\mu$-O bridges can be divided into two groups according their bridging angle which is either close to $97(\mathrm{O} 2 \mathrm{M}$ and $\mathrm{O} 3 \mathrm{M})$ or $111^{\circ}(\mathrm{O} 1 \mathrm{M}$ and $\mathrm{O} 1 \mathrm{H})$. A similar observation is found for the $\mu_{3}-\mathrm{O}$ bridges with values of about $95(\mathrm{O} 1$ and $\mathrm{O} 2)$ and $124^{\circ}(\mathrm{O} 1 \mathrm{M}, \mathrm{O} 2 \mathrm{M}, \mathrm{O} 3 \mathrm{M}$, and $\mathrm{O} 1 \mathrm{H})$. The smaller angles are 
observed for the $\mu$-OMe and $\mu_{3}-\mathrm{O}$ bridges connecting a pair of iron centers within the $\mathrm{Fe}_{3} \mathrm{O}$ fragments $(\mathrm{Fe} 1 \cdots \mathrm{Fe} 2$ and $\mathrm{Fe} 3 \cdots \mathrm{Fe} 4)$ leading to $\mathrm{Fe}_{2} \mathrm{O}_{2}$ units with rather short interatomic $\mathrm{Fe} \cdots \mathrm{Fe}$ distances of about $296 \mathrm{pm}$. All other $\mathrm{Fe} \cdots \mathrm{Fe}$ distances are clearly longer and in the range between 325 and 618 pm (see Table 4).

The obtained crystal structure is consistent with an overall neutral hexanuclear complex, as no indication for counterions can be found. Nevertheless, the actual protonation of the bridging oxygen atoms cannot be directly determined by X-ray crystallography. We therefore performed bond-valence sum (BVS) calculations to confirm the valence state of the iron ions in the complex and the protonation state of the bridging oxygen atoms. For iron compounds it has been shown, that BVS calculations with oxidation-state-independent parameters taken from the original reference of Brown and Altermatt [23], allow to distinguish between complexes of high-spin iron(II) (BVS $=2.30 \pm 0.14$ ), high-spin iron(III) (BVS = $3.04 \pm 0.12)$, and the low-spin state of both iron(II) and iron(III) $\left(\mathrm{BVS}\left(\mathrm{Fe}^{2+}\right)=4.22 \pm 0.23\right.$ and $\left.\mathrm{BVS}\left(\mathrm{Fe}^{3+}\right)=4.10 \pm 0.34\right)[24]$.

The relevant data for compound $\mathbf{1}$ is given in Table 5. The BVS values for the six iron centers are in good agreement with the oxidation and spin state of high-spin iron(III) ions. As the hydrogen atoms in the crystal structure of $\mathbf{1}$ could not be located and refined, the primarily obtained BVS values correspond to a non-protonated situation at the oxygen atoms. In the case of the twofold bridging oxygen atoms the primarily obtained BVS values clearly indicate that in the case of oxygen atom $\mathrm{O} 1 \mathrm{H}$ an additional protonation is present, whereas the oxygen atoms $\mathrm{O} i \mathrm{M}(i=1,2,3)$ are not protonated. This is consistent with three $\mu$-OMe bridges $(\mathrm{O} 1 \mathrm{M}, \mathrm{O} 2 \mathrm{M}$, and $\mathrm{O} 3 \mathrm{M})$ and one $\mu-\mathrm{OH}$ bridge $(\mathrm{O} 1 \mathrm{H})$. Moreover, the protonation of the $\mu$ $\mathrm{OH}$ group is consistent with an observed hydrogen-bonding interaction towards the nitrogen atom N1PA of a co-crystallized pyridine molecule at a distance of $275 \mathrm{pm}(\mathrm{O} 1 \mathrm{H} \cdots \mathrm{N} 1 \mathrm{PA})$. The situation is different for the $\mu_{3}-\mathrm{O}$ bridges, for which the calculated BVSs of about 1.6 are somewhat smaller than the expected value for a oxido group. It is therefore tempting to assume that an additional proton could be located at these oxygen atoms. If a single proton in a symmetric $\mathrm{O} \cdots \mathrm{H} \cdots \mathrm{O}$ hydrogen-bridging mode $(\mathrm{O} 1 \cdots \mathrm{O} 2267 \mathrm{pm})$ is presumed to be present, the a BVS value of about two is obtained for the oxygen atoms $\mathrm{O} 1$ and $\mathrm{O} 2$. Although such $\mathrm{O} \cdots \mathrm{H} \cdots \mathrm{O}$ hydrogen-bridges are well known for even shorter distances [25] and in the coordination environment of iron(III) ions [26,27], to the best of our knowledge, no such case has been reported for $\mu_{3}$-O groups in the vicinity of iron(III) ions. Nevertheless, in a seminal paper Day and Klemperer et al. [28] have reported for decavanadate that it is possible to protonate a triply-bridging oxygen, which in this case is even the preferred protonation site.

However, in the case of complex 1 such a protonation would necessitate a charge compensation, but neither an additional anion can be located in the crystal structure nor does the BVS analysis indicate the presence of an iron(II) ion. Moreover, the steric restraints at the $\mu_{3}$-oxido groups are unfavorable for such an $\mathrm{O} \cdots \mathrm{H} \cdots \mathrm{O}$ hydrogen bonding. Also the rather basic reaction conditions with pyridine as solvent should not lead to such a protonation of the hexanuclear core. We therefore assign the unprotonated form at the $\mu_{3}$-oxido groups to the structure of complex $\mathbf{1}$ which is depicted in Figures 1 and 2. This interpretation is also consistent with the additional analytical data.

\section{Magnetochemistry}

The magnetic susceptibility data for the iron complex $\mathbf{1}$ has been measured in the temperature range from 2 to $300 \mathrm{~K}$. The magnetic data are shown in Figure 3 as temperature-dependent plots of $\chi_{\mathrm{M}}$ and $\chi_{\mathrm{M}} T$. The $\chi_{\mathrm{M}} T$ value at $300 \mathrm{~K}$ is $7.4 \mathrm{~cm}^{3} \mathrm{~K} \mathrm{~mol}{ }^{-1}$, which is significantly lower than the expected spin-only value for six independent high-spin iron(III) ions with 
$S=5 / 2 \quad\left(26.26 \mathrm{~cm}^{3} \mathrm{~K} \mathrm{~mol}^{-1}\right.$ assuming that $\left.g=2\right)$. On the other hand, this value is considerably higher than the spin-only value expected for six uncoupled low-spin iron(III) ions with $S=1 / 2\left(2.25 \mathrm{~cm}^{3} \mathrm{~K} \mathrm{~mol}^{-1}\right.$ assuming that $\left.g=2\right)$ [29]. Upon lowering the temperature the $\chi_{\mathrm{M}} T$ value steadily decreases almost linear, reaching values close to zero at temperatures below $5 \mathrm{~K}$. Together with the very low room temperature value of $\chi_{\mathrm{M}} T$, this temperature characteristic is indicative of an overall strong antiferromagnetic exchange interaction within the hexanuclear high-spin iron(III) core resulting in an $S=0$ spin ground state.

Due to the topology of the hexanuclear core of compound $\mathbf{1}$ at least a three- $J$ model is needed to describe the magnetic data. This is getting even more complicated when the actual variation of bridging groups and modes are considered. Beside the coupling through oxygenbased bridges $\left(\mu-\mathrm{OH}, \mu-\mathrm{OMe}\right.$, and $\left.\mu_{3}-\mathrm{O}\right)$, which is known to be very efficient, the interaction through the $\mathrm{N}-\mathrm{N}$ diazine bridges of the ligand molecules has to be considered. Unfortunately, there is no analytical expression for the analysis of the magnetic interactions of a hexanuclear high-spin iron(III) complex with the given topology. On the other hand, the usual approach by diagonalizing the full spin-Hamiltonian matrix is hampered by large dimensions of the resulting matrix as well as the problem of overparametrization, as the large number of different exchange pathways within the hexanuclear core is considered. Moreover, the almost linear decrease of the $\chi_{\mathrm{M}} T$ value with decreasing temperature clearly limits any attempt, not to say would makes it virtually impossible, to determine meaningful parameters from the magnetic data. We therefore did not attempt to extract any coupling parameters directly from the magnetic data.

On the other hand, magneto-structural correlations are known for iron(III) complexes, which allow to estimate relevant coupling constants. Most of these correlations are based on iron(III) systems containing dinuclear oxido-, hydroxido- and alkoxido-bridges. In all cases, correlations have been established between the exchange coupling constant $J$ and the $\mathrm{Fe}-\mathrm{O}-$ Fe angle $(\alpha)$ or the $\mathrm{Fe}-\mathrm{O}$ distance $(r)$ within the bridging units [30-34]. Weihe and Güdel used a formulation based on the angular overlap model to derive an expression for $J$ including both parameters $r$ as well as $\alpha$ represented in Equation (1) [35].

$$
-J=A\left(B+C \cos \alpha+\cos ^{2} \alpha\right) \exp (D r)
$$

In fact, a fit of this expression to experimental data for a series of oxido- bridged iron(III) dimers indicates that the antiferromagnetic interaction increases when $\alpha$ decreases or when $r$ decreases. This correlation is independent of additional bridging ligands being present. Since for polynuclear complexes a distinct angular dependence had been observed, Christou et al. used the expression from Equation (1) to fit the magnetic data of a series of hexanuclear iron(III) complexes comprising mixed bridging modes including oxido, hydroxido, and alkoxido groups [36]. Based on the spin Hamiltonian defined as $\hat{H}=-J\left(\hat{S}_{1} \hat{S}_{2}\right)$, this has lead to the parameters $A=4 \cdot 10^{7} \mathrm{~cm}^{-1}, B=0.2, C=-1$ and $D=-0.07 \mathrm{pm}^{-1}$. Moreover, it was found that whenever more than one bridge is present between two iron centers, the best results are obtained by employing the average distance for the shortest $\mathrm{Fe}-\mathrm{O}$ bridge, which in generally corresponds also to the one with the widest $\mathrm{Fe}-\mathrm{O}-\mathrm{Fe}$ angle.

Applying this relationship to the hexanuclear iron(III) complex $\mathbf{1}$ this results in the $J$ values listed in Table 6, which correspond to the coupling scheme depicted in Scheme 3. This neglects in accordance with the utilized magnetostructural relationship any significant contribution via the additional diazine bridges present between the rim iron centers ( $\mathrm{Fe} 1, \mathrm{Fe} 2$, $\mathrm{Fe} 3$, and $\mathrm{Fe} 4$ ) of the paddle wheel and to two iron centers (Fe5 and $\mathrm{Fe} 6$ ) at the axle. The simulated [37] temperature dependence of $\chi_{\mathrm{M}} T$ utilizing the derived parameters is shown as solid line in Figure 3. A slightly reduced $g$-value of 1.79 had to be used, which is lower than 
the expected value for an iron(III) high spin $(g \approx 2)$, but it should be kept in mind, that the $g$-value is affected most by all kinds of experimental error and that paramagnetic impurities (indicated by the increase of $\chi_{\mathrm{M}}$ below $10 \mathrm{~K}$ ) as well as temperature independent paramagnetism could not be included in the simulation. Despite these constraints the simulated behavior is in good agreement with the experimental data.

As expected, all estimated $\mathrm{Fe}_{m}-\mathrm{Fe}_{n}$ exchange constants $\left(J_{m n}\right)$ through the oxygen bridges are antiferromagnetic with values in the range between -11 and $-45 \mathrm{~cm}^{-1}$. Within the rim of the paddle wheel the exchange constants can be divided into two groups corresponds to the observed angles at the bridging oxygen atoms (cf. Table 3). The smallest couplings are assigned to the pairs $\mathrm{Fe} 1-\mathrm{Fe} 2$ and $\mathrm{Fe} 3-\mathrm{Fe} 4$ bridged by $\mu$-OMe and $\mu_{3}-\mathrm{O}$ groups with values of $J_{12}=-11$ and $J_{34}=-13 \mathrm{~cm}^{-1}$. Significantly larger values are attributed to the other two pairs $\mathrm{Fe} 1-\mathrm{Fe} 4$ and $\mathrm{Fe} 2-\mathrm{Fe} 3$ bridged by a $\mu$-OMe and a $\mu_{3}-\mathrm{OH}$ group, respectively, with $J_{14}=-28$ and $J_{23}=-36 \mathrm{~cm}^{-1}$. The largest couplings are expected for the exchange pathways between pairs consisting of an iron centers at the axel and the relevant iron centers of the rim forming the $\mathrm{Fe}_{3} \mathrm{O}$ fragments $\left(J_{15}, J_{25}, J_{36}\right.$, and $\left.J_{46}\right)$ with values of about $-40 \mathrm{~cm}^{-1}$.

This leads to a significant difference in strength between the coupling constants. The resulting spin alignments within 1 are indicated in Scheme 3. Within the trinuclear $\mathrm{Fe}_{3} \mathrm{O}$ fragments this results in competing exchange interactions with a parallel alignment of spins along the exchange pathways $\mathrm{Fe} 1-\mathrm{Fe} 2$ and $\mathrm{Fe} 3-\mathrm{Fe} 4$, which is in contrast to the antiferromagnetic coupling between these iron centers. Similar situations of competing magnetic exchange interactions have been reported in the literature [38,39]. According to the notation of Kahn [40] the exchange pathways $\mathrm{Fe} 1-\mathrm{Fe} 2$ and $\mathrm{Fe} 3-\mathrm{Fe} 4$ can be regarded as frustrated. Due to the antiparallel alignment along the $\mathrm{Fe} 1-\mathrm{Fe} 4$ and $\mathrm{Fe} 2-\mathrm{Fe} 3$ pathways an overall $S=0$ spin ground state results for the hexanuclear compound $\mathbf{1}$, which is consistent with the experimental data.

\section{Conclusions}

Attempts to utilize 2,6-di(pyrazol-3-yl)pyridine $\left(\mathrm{H}_{2} \mathrm{bpp}\right)$ as a meridional capping ligand for trinucleating core fragments based on the triaminoguanidine ligand system failed, due to a subtle balance between the homoleptic and mononuclear species on the one hand and the desired heteroleptic trinuclear system on the other hand. Instead, under aerobic and basic conditions the $\{\mathrm{Fe}(\mathrm{III}) \mathrm{bpp}\}^{+}$subunits are formed, which assemble to the hexanuclear complex 1 with additional oxido, hydroxido, and methoxido bridging ligands.

Utilizing the appropriate stoichiometry, the hexanuclear iron(III) complex $\mathbf{1}$ can be deliberately synthesized in high yield as the first oligonuclear complex with $\mathrm{H}_{2}$ bpp as a capping ligand. The paddle-wheel like structure is composed of six iron(III) ions in a distorted octahedral coordination geometry. The six iron centers can be divided into two $\mathrm{Fe}_{3} \mathrm{O}$ fragments with a $\mu_{3}$-oxido bridge. The magnetic data suggests an overall $S=0$ spin ground state with antiferromagnetic exchange interactions between the iron centers. A simulation confirms the assignment of the exchange constants, leading a situation with two frustrated exchange pathways, one within each of the $\mathrm{Fe}_{3} \mathrm{O}$ fragments.

\section{Experimental Section}

Materials: The ligand 2,6-di(pyrazol-3-yl)pyridine $\left(\mathrm{H}_{2} \mathrm{bpp}\right)$ was synthesized according to a published procedure starting from 2,6-diacetylpyridine [16]. All other starting chemicals are commercially available and were used without further purification. 
Physical Measurements: The melting point is given uncorrected and was determined with a VEB Analytik Dresden HMK 72/41555. The infrared spectra were recorded on a Bruker IFS55/EQUINOX spectrometer. Mass spectra were measured on a Bruker MAT SSQ 710 spectrometer. Elemental analyses were determined on a Leco CHNS/932 and a VARIO EL III elemental analyzer. Magnetic susceptibilities were obtained for a polycrystalline sample using a Quantum-Design MPMSR-5S SQUID magnetometer, measurements were performed with an applied magnetic field of 2000 and $5000 \mathrm{Oe}$ in the temperature range from 300 to $2 \mathrm{~K}$. The measured values of the molar magnetic susceptibility $\chi_{\mathrm{M}}$ were corrected with respect to diamagnetic contributions.

$\left[\mathbf{F e}_{6}(\mathbf{b p p})_{4}\left(\mu_{3}-\mathbf{O}\right)_{2}(\mu-\mathbf{O M e})_{3}(\mu-\mathbf{O H}) \mathbf{C l}_{2}\right]$ (1): The ligand $\mathrm{H}_{2}$ bpp (160 mg, $\left.0.8 \mathrm{mmol}\right)$ was added in portions to a stirred solution of $\mathrm{FeCl}_{2} \cdot 4 \mathrm{H}_{2} \mathrm{O}(226 \mathrm{mg}, 1.1 \mathrm{mmol})$ in methanol/pyridine mixture $(1: 1,15 \mathrm{~mL})$. The color changed immediately from yellow to red. The reaction mixture was stirred for additional $15 \mathrm{~min}$, during which period the color intensified to deep red. Slow diffusion of methanol into the reaction mixture within two weeks yields red prism of $1 \cdot 1.5$ py suitable for X-ray crystallography. These were isolated, washed with methanol, and finally dried in air, upon which the crystals loose the pyridine of crystallization. (Yield: $190 \mathrm{mg}, 70 \%)$. Mp. > $200{ }^{\circ} \mathrm{C}$. IR (KBr): 3435 (s br, $v(\mathrm{OH})$ ), 3111, 3083, 3056 (all w, v(CH) arom.), $2918\left(\mathrm{~m}, v_{a s}\left(\mathrm{CH}_{3}\right)\right), 2814\left(\mathrm{~m}, v_{s}\left(\mathrm{CH}_{3}\right)\right), 1610,1571$, 1464 (all vs, $v_{a s}(\mathrm{C}=\mathrm{C})$ arom.), 1433 (m), 1352 (vs), 1324 (w), 1157 (s) 1146 (vs), 1121 (vs), 1070 (m), 975 (m), 943 (m), 770 (vs), 666 (w), 646 (w), 547 (m br), 493 (vs br, $v(\mathrm{Fe}-\mathrm{Cl})$ ) $\mathrm{cm}^{-1}$. MS (ESI $\left.{ }^{+} \mathrm{DMF} / \mathrm{MeOH}\right) \quad m / z 1349\left(100 \%, \quad\left[\mathrm{Fe}_{6}(\mathrm{bpp})_{4}\left(\mu_{3}-\mathrm{O}\right)_{2}(\mu-\mathrm{OMe})_{3}(\mu-\right.\right.$ $\left.\mathrm{OH}) \mathrm{Cl}]^{+}\right), 1313\left(85 \%,\left[\mathrm{Fe}_{6}(\mathrm{bpp})_{4}\left(\mu_{3}-\mathrm{O}\right)_{2}(\mu-\mathrm{OMe})_{3}(\mu-\mathrm{O})\right]^{+}\right) .\left[\mathrm{Fe}_{6}(\mathrm{bpp})_{4}\left(\mu_{3}-\mathrm{O}\right)_{2}(\mu-\right.$ $\left.\mathrm{OMe})_{3}(\mu-\mathrm{OH}) \mathrm{Cl}_{2}\right], \mathrm{C}_{47} \mathrm{H}_{38} \mathrm{Cl}_{2} \mathrm{Fe}_{6} \mathrm{~N}_{20} \mathrm{O}_{6}$ (1384.91 g/mol): C 40.76 (calc. 41.24); $\mathrm{H} 2.77$ (3.36); N $20.23(20.67) \%$.

X-ray Crystallographic Studies: X-ray measurements were carried out with a Nonius Kappa CCD diffractometer using graphite monochromated Mo-K $\alpha$ radiation $(\lambda=71.073 \mathrm{pm})$ at 183(2) K. The crystallographic data are summarized in Table 7. Data were corrected for Lorentz and polarization effects, but not for absorption effects [41-43]. The structures were solved by direct methods with SHELXS-97 and refined by full-matrix least-squares techniques against $F_{o}^{2}$ using SHELXL-97 [44]. The hydrogen atoms were included at calculated positions with fixed thermal parameters. All non-hydrogen atoms were refined anisotropically. One of the co-crystallized pyridine molecules is located in hydrogen-bonding distance from the $\mu-\mathrm{OH}$ group, whereas the additional 0.5 molecules are found to be orientationally disordered at a partially filled position with occupancy factors of 0.5 . This position is within an hydrophobic region in the crystal structure build by the pyrazolido ligands at the axle of the paddle-wheel structure. Crystallographic data for complex 1.1.5 py have been deposited with the Cambridge Crystallographic Data Centre CCDC 761355. Copies of the data can be obtained free of charge on application to The Director, CCDC, 12 Union Road, Cambridge CB2 1EZ, UK (Fax: int.code+(1223)336-033; e-mail for inquiry: fileserv@ccdc.cam.ac.uk).

Acknowledgement. We thank the Deutsche Forschungsgemeinschaft for financial support (SPP 1137). The support by a Graduiertenstipendium of the Freistaat Thüringen (D.P. and E.T.S.) as well as the Carl-Zeiss-Stiftung (E.T.S.) is gratefully acknowledged. 


\section{References}

[1] E. Constable, Advances in Inorganic Chemistry, Vol. 30, Academic Press, 1986, pp. 69121.

[2] U. S. Schubert, H. Hofmeier, G. R. Newkome, Modern Terpyridine Chemistry, WileyVCH Inc., 2006.

[3] T. J. Meyer, M. H. V. Huynh, Inorg. Chem. 2003, 42, 8140-8160.

[4] M. A. Halcrow, Coord. Chem. Rev. 2005, 249, 2880-2908.

[5] K. Sugiyarto, D. C. Craig, A. Rae, H. Goodwin, Aust. J. Chem. 1994, 47, 869-890.

[6] K. Sugiyarto, H. Goodwin, Aust. J. Chem. 1988, 41, 1645.

[7] K. Sugiyarto, K. Weitzner, D. C. Craig, H. Goodwin, Aust. J. Chem. 1997, 50, 869-873.

[8] S. Marcén, L. Lecren, L. Capes, H. A. Goodwin, J. F. Létard, Chem. Phys. Lett. 2002, 358, 87-95.

[9] E. Coronado, M. C. Giménez-López, C. Gimenez-Saiz, J. M. Martínez-Agudo, F. M. Romero, Polyhedron 2003, 22, 2375-2380.

[10] K. H. Sugiyarto, W.-A. McHale, D. C. Craig, A. D. Rae, M. L. Scudder, H. A. Goodwin, Dalton Trans. 2003, 2443-2448.

[11] P. Gamez, R. H. Steensma, W. L. Driessen, J. Reedijk, Inorg. Chim. Acta 2002, 333, 51 $-56$.

[12] G. Dong, J. P. Matthews, D. C. Craig, A. T. Baker, Inorg. Chim. Acta 1999, 284, 266272.

[13] D. A. Bardwell, J. C. Jeffery, P. L. Jones, J. A. McCleverty, E. Psillakis, Z. Reeves, M. D. Ward, J. Chem. Soc., Dalton Trans. 1997, 2079-2086.

[14] Y. Zhou, W. Chen, Dalton Trans 2007, 5123-5125.

[15] W. Plass, Coord. Chem. Rev. 2009, 253, 2286--2295.

[16] A.-K. Pleier, H. Glas, M. Grosche, P. Sirsch, W. R. Thiel, Synthesis 2001, 55-62.

[17] A.E. Ion, E.T. Spielberg, H. Görls, W. Plass, Inorg. Chim. Acta 2007, 360, 3925-3931.

[18] A. Zharkouskaya, A. Buchholz, W. Plass, Eur. J. Inorg. Chem. 2005, 4875-4879.

[19] A. Zharkouskaya, H. Görls, G. Vaughan, W. Plass, Inorg. Chem. Commun. 2005, 8, $1145-1148$.

[20] G.J. Long, D.L. Whitney, J.E. Kennedy, Inorg. Chem., 1971, 10, 1406-1410.

[21] O. Baudischan, W.H. Hartung, Inorg. Syn. 1939, 1, 184-185.

[22] A. G. Orpen, L. Brammer, F. H. Allen, O. Kennard, D. G. Watson, R. Taylor, J. Chem. Soc., Dalton Trans. 1989, S1-S83.

[23] I. D. Brown, D. Altermatt, Acta Cryst. B 1985, 41, 244-247.

[24] R.C. Scarrow, B.A. Brennan, J.G. Cummings, H. Jin, D.J. Duong, J.T. Kindt, M.J. Nelson, Biochemistry 1996, 35, 10078-10088

[25] W. Plass, A. Pohlmann, J. Rautengarten, Angew. Chem. 2001, 113, 4333-4336; Angew. Chem., Int. Ed. 2001, 40, 4207-4210.

[26] W. Micklitz, S.J. Lippard, Inorg. Chem. 1988, 27, 3067-3069.

[27] T. Tanase, C. Inoue, E. Ota, S. Yano,M. Takahashi, M. Takeda, Inorg. Chim. Acta 2000, 297, 18-26.

[28] V.W. Day, W.G. Klemperer, D.J. Maltbie, J. Am. Chem. Soc 1987, 109, 2991-3002.

[29] O. Kahn, Molecular Magnetism, Wiley-VCH Inc., Weinheim, 1993.

[30] M. Gerloch, E.D. McKenzie, A.D.C. Towl, J. Chem. Soc. (A) 1969, 2850-2858.

[31] D.M. Kurtz, Chem. Rev. 1990, 90, 585-606.

[32] S.M. Gorun, S.J. Lippard, Inorg. Chem. 1991, 30, 1625-1630.

[33] F. Le Gall, F. F. de Biani, A. Caneschi, P. Cinelli, A. Cornia, A. C. Fabretti, D. Gatteschi, Inorg. Chim. Acta 1997, 262, 123-132.

[34] O. Waldmann, R. Koch, S. Schromm, J. Schulein, P. Muller, I. Bernt, R.W. Saalfrank, F. Hampel, E. Balthes, Inorg. Chem. 2001, 40, 2986-2995. 
[35] H. Weihe, H.U. Güdel, J. Am. Chem. Soc. 1997, 119, 6539-6543.

[36] C. Canada-Vilalta, T.A. O’Brien, E.K. Brechin, M. Pink, E. R. Davidson, G. Christou, Inorg. Chem. 2004, 43, 5505-5521.

[37] J. Borras-Almenár, J. Clemente-Juan, E. Coronado, B. Tsukerblat, Journal of Computational Chemistry 2001, 22, 985-991.

[38] J.K. McCusker, J.B. Vincent, E.A. Schmitt, M.L. Mino, K. Shin, D. Coggin, P.M. Hagen, J.C. Huffman, G. Christou, D.N. Hendrickson, J. Am. Chem. Soc. 1991, 113, 3012-3021.

[39] W. Plass, Inorg. Chem. 1997, 36, 2200-2205

[40] O. Kahn, Chem. Phys. Lett. 1997, 265, 109-114.

[41] SMART COLLECT, Data Collection Software, Nonius B.V., Netherlands, 1998.

[42] Z. Otwinowski, W. Minor, Processing of x-ray diffraction data collected in oscillation mode, in: C. W. Carter, R. M. Sweet (Eds.), Macromolecular Crystallography, Part A, Vol. 276 of Methods in Enzymology, Academic Press, San Diego, 1997, pp. 307-326.

[43] SMART, Software for the CCD Detektor System, version 5.05: Bruker AXS: Madison, WI, 1998.

[44] G. M. Sheldrick, SHELXS97 and SHELXL97, University of Göttingen, Germany, 1997. 
Scheme 1. The 2,6-di(pyrazol-3-yl)pyridine ligand ( $\mathrm{H}_{2}$ bpp).

Scheme 2. Tritopic triaminoguanidine core $\left[\mathrm{H}_{6} \mathrm{~L}\right]^{+}$.

Scheme 3. Schematic representation of the exchange pathways through the bridging oxygen atoms. The arrows indicate alignment of the unpaired electrons of the iron centers.

Figure 1. Molecular structure of compound $\left[\mathrm{Fe}_{6}(\mathrm{bpp})_{4}\left(\mu_{3}-\mathrm{O}\right)_{2}(\mu-\mathrm{OMe})_{3}(\mu-\mathrm{OH}) \mathrm{Cl}_{2}\right](\mathbf{1})$. The hydrogen atoms are omitted for clarity.

Figure 2. Representation of the $\mathrm{Fe}_{6}$ core unit of compound 1. Only the coordinating nitrogen atoms of the ligands are shown.

Figure 3. Plots of $\chi_{M}(\circ)$ and $\chi_{M} T(\bullet)$ vs. $T$ for compound 1 . The solid line represents the simulation (for details see text). 
Table 1. Selected bond lengths [pm] and angles $\left[{ }^{\circ}\right]$ for complex $\mathbf{1}$.

$\begin{array}{llll}\text { Fe1-O1 } & 199.4(5) & \text { Fe2-O1 } & 203.3(5) \\ \text { Fe1-O1M } & 198.2(5) & \text { Fe2-O1H } & 194.4(5) \\ \text { Fe1-O3M } & 198.5(5) & \text { Fe2-O3M } & 198.3(5) \\ \text { Fe1-N2 } & 206.4(6) & \text { Fe2-N7 } & 206.4(6) \\ \text { Fe1-N3 } & 220.5(6) & \text { Fe2-N8 } & 220.6(6) \\ \text { Fe1-N4 } & 217.5(6) & \text { Fe2-N9 } & 217.5(6) \\ \text { Fe3-O2 } & 201.0(5) & \text { Fe4-O2 } & 203.2(5) \\ \text { Fe3-O1H } & 193.5(5) & \text { Fe4-O1M } & 196.5(5) \\ \text { Fe3-O2M } & 199.5(5) & \text { Fe4-O2M } & 196.8(5) \\ \text { Fe3-N12 } & 218.3(6) & \text { Fe4-N17 } & 218.8(6) \\ \text { Fe3-N13 } & 219.8(6) & \text { Fe4-N18 } & 219.8(6) \\ \text { Fe3-N14 } & 205.7(6) & \text { Fe4-N19 } & 207.5(6) \\ \text { Fe5-O1 } & 194.0(5) & \text { Fe6-O2 } & 192.0(5) \\ \text { Fe5-N1 } & 212.8(7) & \text { Fe6-N5 } & 213.3(6) \\ \text { Fe5-N6 } & 212.4(6) & \text { Fe6-N10 } & 210.4(6) \\ \text { Fe5-N11 } & 213.2(6) & \text { Fe6-N15 } & 213.0(6) \\ \text { Fe5-N16 } & 211.6(6) & \text { Fe6-N20 } & 212.1(6) \\ \text { Fe5-C11 } & 240.4(2) & \text { Fe6-C12 } & 242.6(2) \\ & & & \\ \text { O1-Fe1-N3 } & 154.40(22) & \text { O1-Fe2-N8 } & 153.44(22) \\ \text { O1M-Fe1-O3M } & 158.02(20) & \text { O1H-Fe2-O3M } & 161.11(20) \\ \text { N2-Fe1-N4 } & 143.93(23) & \text { N7-Fe2-N9 } & 143.75(23) \\ \text { O2-Fe3-N13 } & 153.17(21) & \text { O2-Fe4-N18 } & 153.66(22) \\ \text { O2M-Fe3-O1H } & 158.34(19) & \text { O1M-Fe4-O2M } & 161.88(19) \\ \text { N12-Fe3-N14 } & 144.96(22) & \text { N17-Fe4-N19 } & 144.15(22) \\ \text { O1-Fe5-C11 } & 170.73(16) & \text { O2-Fe6-C12 } & 170.92(16) \\ \text { N1-Fe5-N11 } & 174.74(23) & \text { N5-Fe6-N15 } & 175.73(22) \\ \text { N6-Fe5-N16 } & 174.11(23) & \text { N10-Fe6-N20 } & 173.30(23)\end{array}$


Table 2. Fe-N-N-Fe torsion angles $\left[{ }^{\circ}\right]$ for complex $\mathbf{1}$.

$\begin{array}{llll}\text { Fe1-N2-N1-Fe5 } & 173.8 & \text { Fe3-N12-N11-Fe5 } & 169.6 \\ \text { Fe1-N4-N5-Fe6 } & 172.7 & \text { Fe3-N14-N15-Fe6 } & 179.6 \\ \text { Fe2-N7-N6-Fe5 } & 179.4 & \text { Fe4-N17-N16-Fe5 } & 175.6 \\ \text { Fe2-N9-N10-Fe6 } & 179.9 & \text { Fe4-N19-N20-Fe6 } & 177.9\end{array}$


Table 3. Fe-O-Fe bridging angles $\left[{ }^{\circ}\right]$ for complex 1 .

$\begin{array}{llll}\text { Fe1-O3M-Fe2 } & 96.3 & \text { Fe3-O2M-Fe4 } & 97.1 \\ \text { Fe1-O1-Fe2 } & 94.5 & \text { Fe3-O2-Fe4 } & 94.5 \\ \text { Fe1-O1M-Fe4 } & 110.8 & \text { Fe2-O1H-Fe3 } & 111.9 \\ \text { Fe1-O1-Fe5 } & 124.8 & \text { Fe3-O2-Fe6 } & 124.6 \\ \text { Fe2-O1-Fe5 } & 122.9 & \text { Fe4-O2-Fe6 } & 123.7\end{array}$


Table 4. Interatomic Fe $\cdots$ Fe separations [pm] for complex 1.

$\begin{array}{llll}\mathrm{Fe} 1 \cdots \mathrm{Fe} 2 & 295.6 & \mathrm{Fe} 3 \cdots \mathrm{Fe} 4 & 297.0 \\ \mathrm{Fe} 1 \cdots \mathrm{Fe} 3 & 442.4 & \mathrm{Fe} 2 \cdots \mathrm{Fe} 4 & 434.4 \\ \mathrm{Fe} 1 \cdots \mathrm{Fe} 4 & 324.9 & \mathrm{Fe} 2 \cdots \mathrm{Fe} 3 & 321.4 \\ \mathrm{Fe} 1 \cdots \mathrm{Fe} 5 & 348.7 & \mathrm{Fe} 3 \cdots \mathrm{Fe} 6 & 348.1 \\ \mathrm{Fe} 1 \cdots \mathrm{Fe} 6 & 408.4 & \mathrm{Fe} 3 \cdots \mathrm{Fe} 5 & 409.4 \\ \mathrm{Fe} 2 \cdots \mathrm{Fe} 5 & 349.1 & \mathrm{Fe} 4 \cdots \mathrm{Fe} 6 & 348.5 \\ \mathrm{Fe} 2 \cdots \mathrm{Fe} 6 & 403.9 & \mathrm{Fe} 4 \cdots \mathrm{Fe} 5 & 404.6 \\ \mathrm{Fe} 5 \cdots \mathrm{Fe} 6 & 617.6 & & \end{array}$


Table 5. BVS ${ }^{a)}$ values for selected atoms in the crystal structure of 1; values including hydrogen atoms at preset distances as used in the solution of the crystal structure are given in parentheses.

\begin{tabular}{|c|c|c|c|}
\hline Fel & 2.93 & $\mathrm{O} 1$ & 1.62 \\
\hline $\mathrm{Fe} 2$ & 2.93 & $\mathrm{O} 2$ & 1.63 \\
\hline $\mathrm{Fe} 3$ & 2.98 & $\mathrm{O} 1 \mathrm{M}$ & 2.02 \\
\hline $\mathrm{Fe} 4$ & 2.91 & $\mathrm{O} 2 \mathrm{M}$ & 1.96 \\
\hline $\mathrm{Fe} 5$ & 2.85 & $\mathrm{O} 3 \mathrm{M}$ & 1.96 \\
\hline Fe6 & 2.87 & $\mathrm{O} 1 \mathrm{H}$ & $1.23(2.23)$ \\
\hline
\end{tabular}

a) $\operatorname{BVS}=\sum_{i} \exp \left[\left(r_{0, i}-r_{i}\right) / B\right] \quad$ with $\quad B=37 \mathrm{pm}, \quad r_{0, F e-O}=175.9 \mathrm{pm}, \quad r_{0, F e-N}=183.7 \mathrm{pm}$, $r_{0, F e-C l}=206.9 \mathrm{pm}, r_{0, C-O}=139.0 \mathrm{pm}$, and $r_{0, O-H}=95.0 \mathrm{pm}$. Parameters are according to ref. [23]. 
Table 6. Calculated $J$ values $\left[\mathrm{cm}^{-1}\right]$ for pairwise $\mathrm{Fe}-\mathrm{Fe}$ interactions through the oxygen bridges in complex 1 based on Equation (1).

$\begin{array}{llll}\text { Fe1-Fe2 } & -11 & \text { Fe3-Fe4 } & -13 \\ \text { Fe1-Fe4 } & -28 & \text { Fe2-Fe3 } & -36 \\ \text { Fe1-Fe5 } & -45 & \text { Fe3-Fe6 } & -45 \\ \text { Fe2-Fe5 } & -37 & \text { Fe4-Fe6 } & -41\end{array}$


Table 7. Crystallographic data and structure-refinement parameters for complex 1.

Complex

Empirical formula

Formula weight

Crystal system

Space group

a (pm)

$\mathrm{b}(\mathrm{pm})$

$\mathrm{c}(\mathrm{pm})$

$\alpha\left({ }^{\circ}\right)$

$\beta\left({ }^{\circ}\right)$

$\gamma\left({ }^{\circ}\right)$

$\mathrm{V}\left(\mathrm{nm}^{3}\right)$

Z

Crystal size (mm)

$D_{\text {calcd }}\left(\mathrm{Mg} \mathrm{m}^{-3}\right)$

$\mu\left(\mathrm{mm}^{-1}\right)$

$\theta$ Range of data collection $\left({ }^{\circ}\right)$

Measured reflections

Unique reflections/ $R_{\text {int }}$

Goodness-of-fit on $F^{2}$

Flack parameter

$R$ indices (all data) ${ }^{a}$ )

Final $R$ indices $[F>2 \sigma(F)]^{a)}$ $\mathbf{1} \cdot 1.5$ py

$\mathrm{C}_{54.5} \mathrm{H}_{45.5} \mathrm{Cl}_{2} \mathrm{Fe}_{6} \mathrm{~N}_{21.5} \mathrm{O}_{6}$

1503.62

monoclinic

$P 2_{1}$

1192.71(4)

2262.81(6)

$1223.15(4)$

90

$113.7820(10)$

90

$3.02082(16)$

2

$0.6 \times 0.6 \times 0.6$

1.653

1.560

$1.87,27.49$

21096

$13570 / 0.0504$

1.031

$0.00(2)$

$R_{1}=0.0984, w R_{2}=0.1445$

$R_{1}=0.0600, w R_{2}=0.1271$

a) $R_{1}=\sum\left(\| F_{o}|-| F_{c}||\right) / \sum\left|F_{o}\right|, w R_{2}=\left(\sum w\left(F_{o}{ }^{2}-F_{c}{ }^{2}\right)^{2} / \sum w\left(F_{o}{ }^{2}\right)^{2}\right)^{\frac{1}{2}}$. 


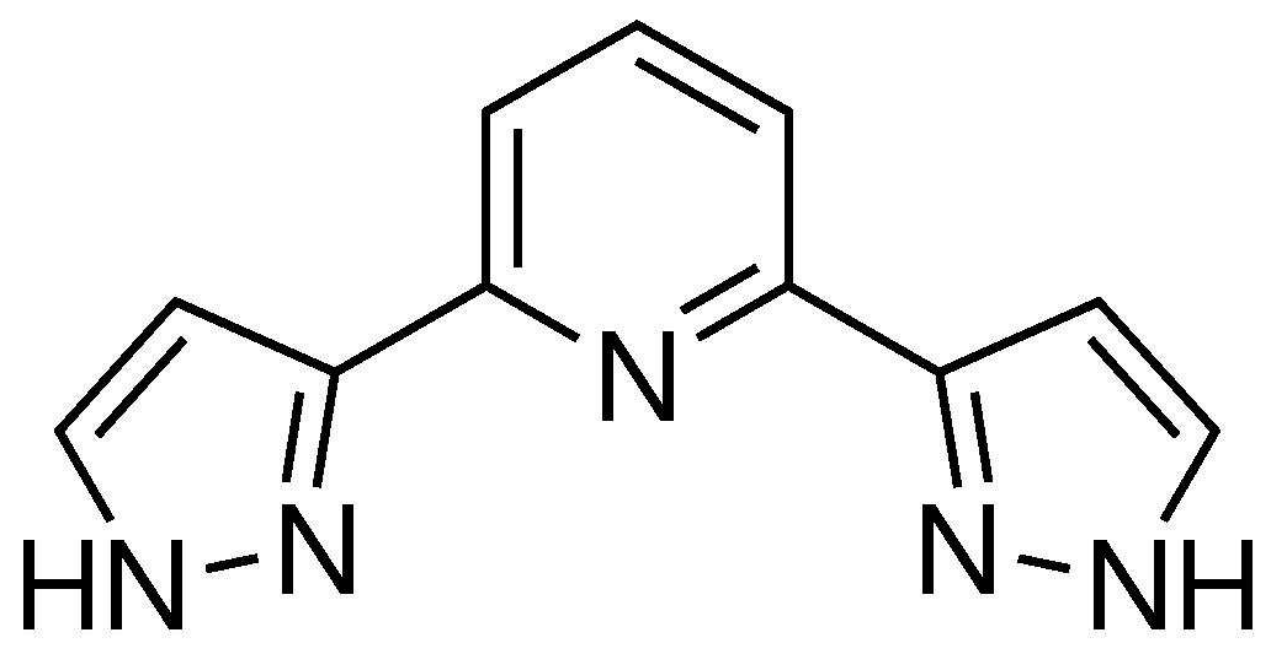

The 2,6-di(pyrazol-3-yl)pyridine ligand ( $\mathrm{H}_{2}$ bpp $)$.

$44 \times 22 \mathrm{~mm}(600 \times 600 \mathrm{DPI})$ 


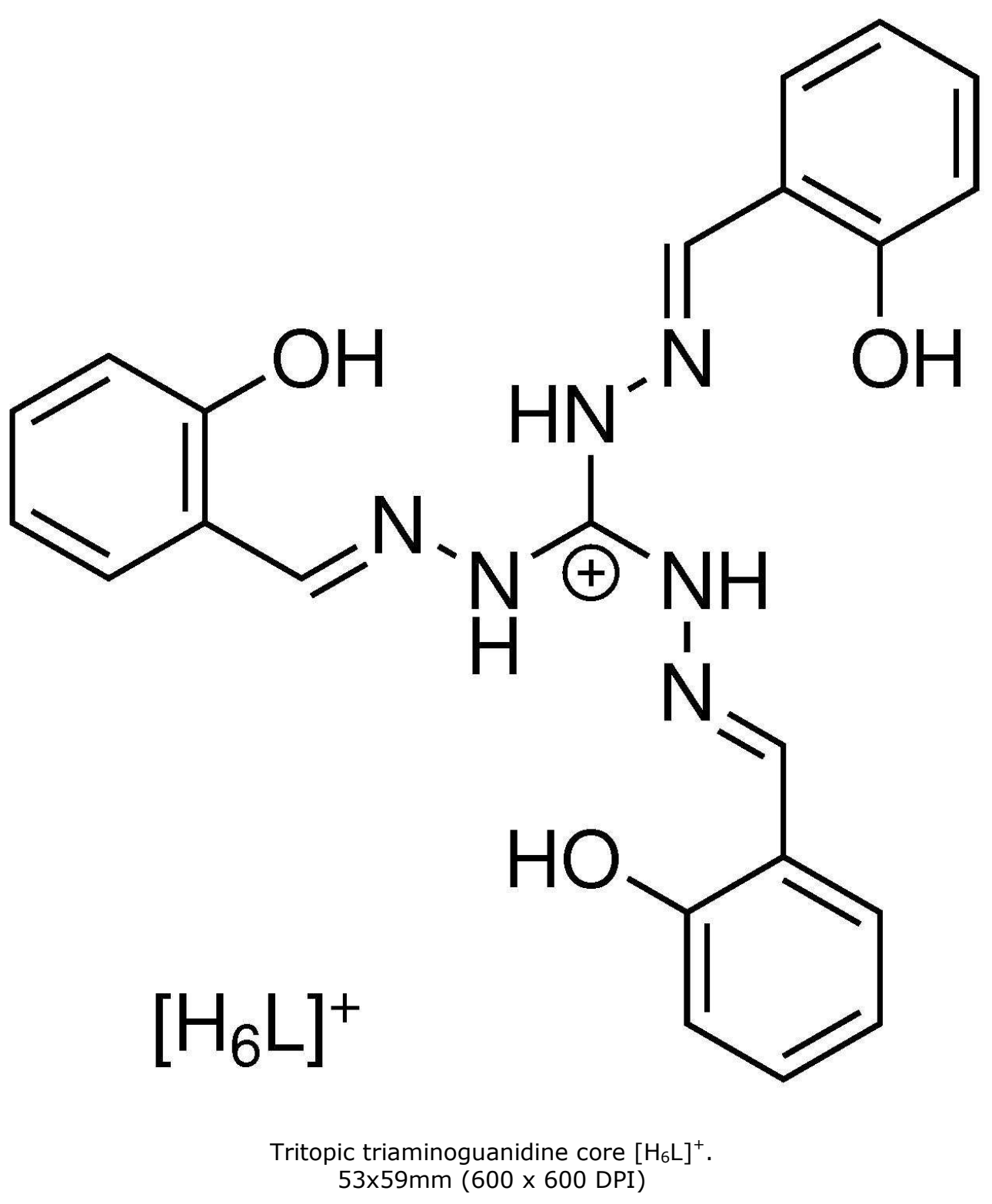




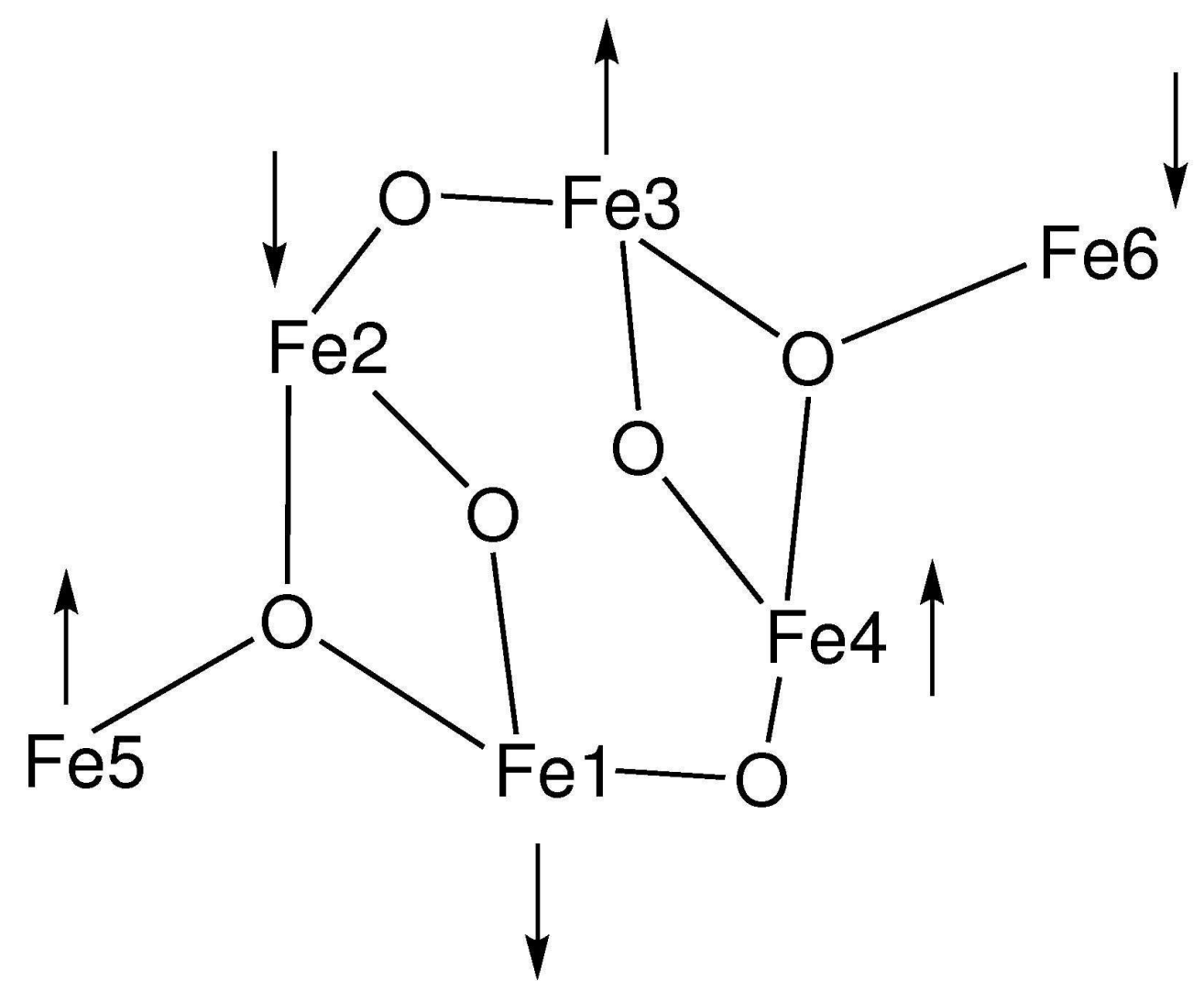

Schematic representation of the exchange pathways through the bridging oxygen atoms. The arrows indicate alignment of the unpaired electrons of the iron centers. $69 \times 58 \mathrm{~mm}(600 \times 600 \mathrm{DPI})$ 


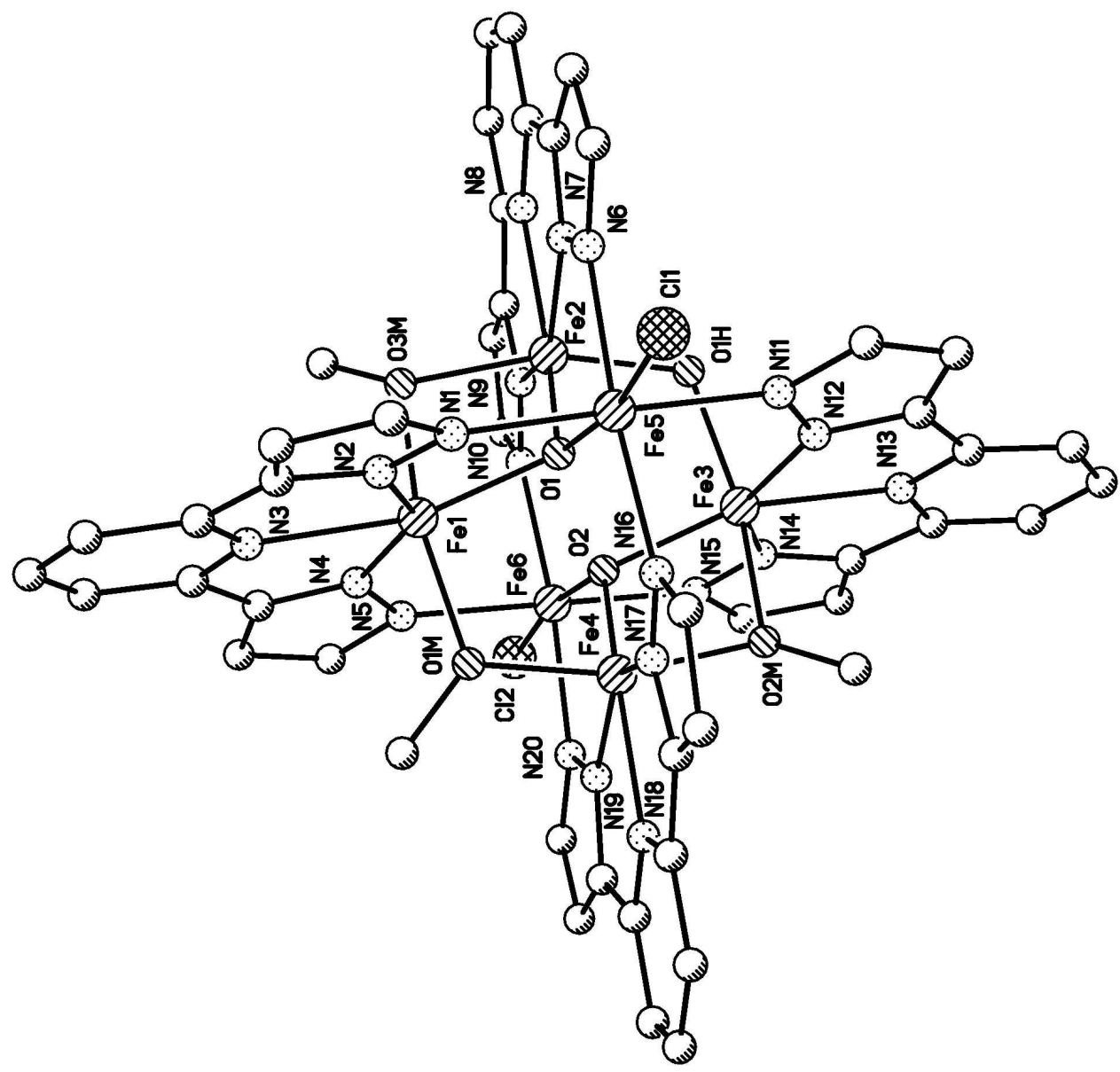

Molecular structure of compound $\left[\mathrm{Fe}_{6}(\mathrm{bpp})_{4}\left(\mu_{3}-\mathrm{O}\right)_{2}(\mu-\mathrm{OMe})_{3}(\mu-\mathrm{OH}) \mathrm{Cl}_{2}\right](\mathbf{1})$. The hydrogen atoms are omitted for clarity. $168 \times 160 \mathrm{~mm}(600 \times 600 \mathrm{DPI})$ 


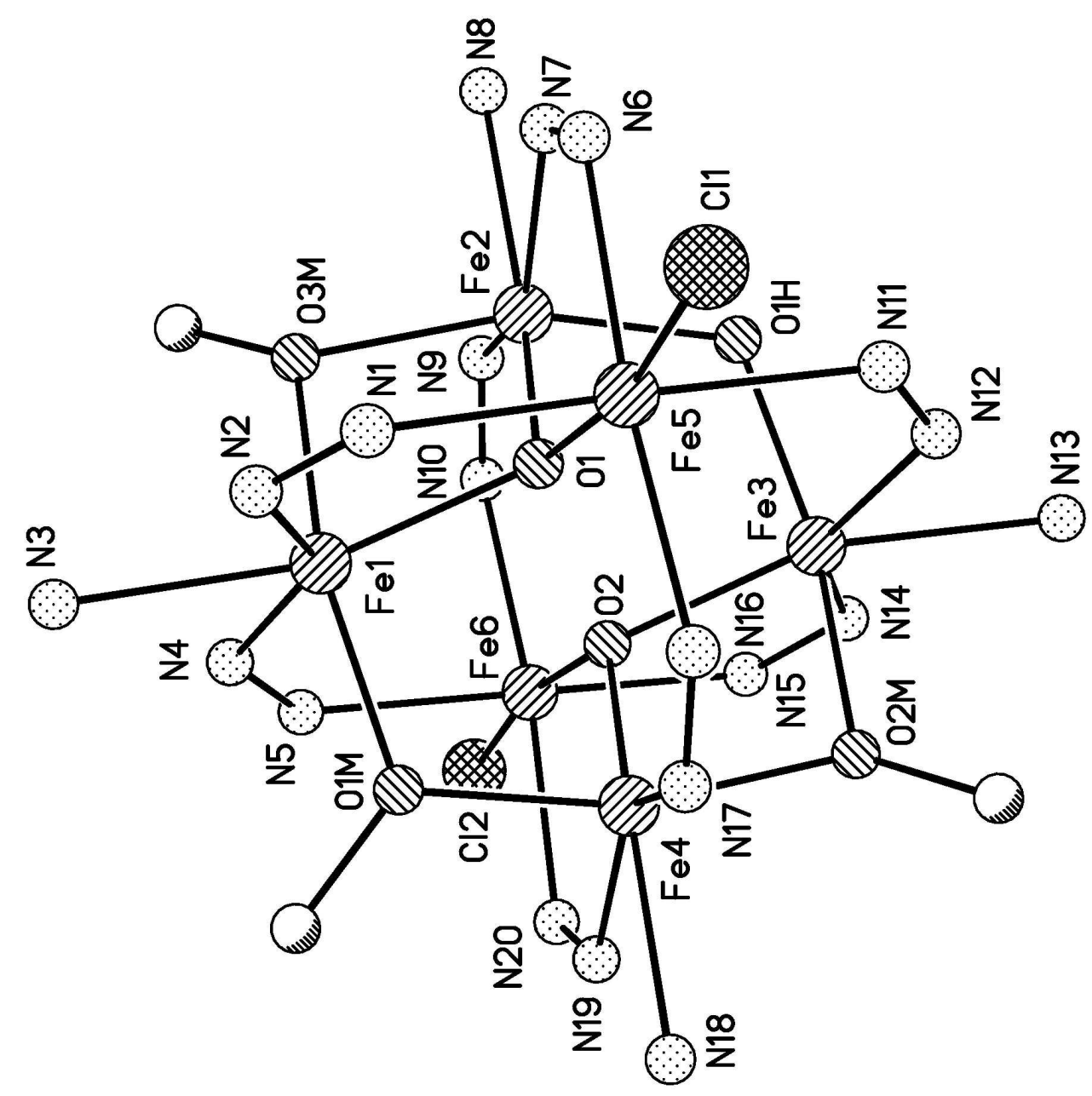

Representation of the $\mathrm{Fe}_{6}$ core unit of compound $\mathbf{1}$. Only the coordinating nitrogen atoms of the ligands are shown. $158 \times 159 \mathrm{~mm}(600 \times 600 \mathrm{DPI})$ 


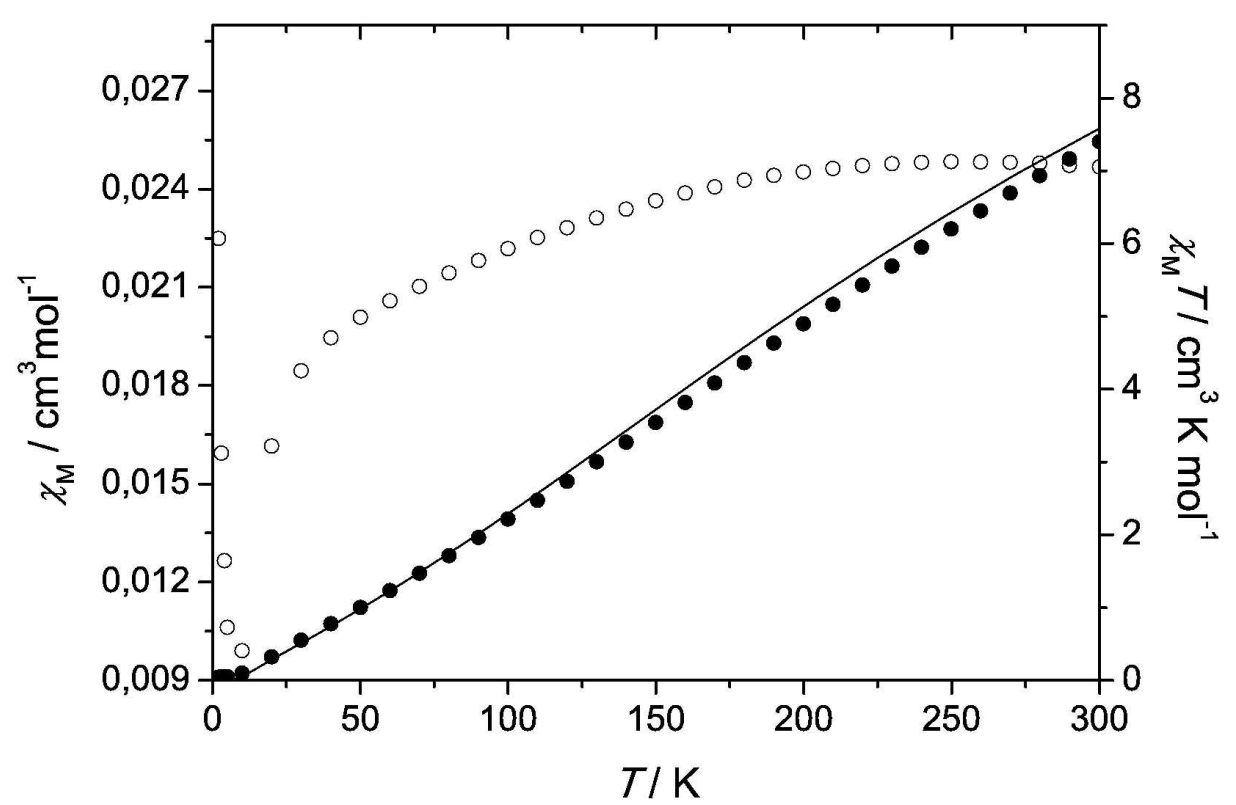

Plots of $X_{M}(0)$ and $X_{M} T(\bullet)$ vs. $T$ for compound $\mathbf{1}$. The solid line represents the simulation (for details see text).

$150 \times 105 \mathrm{~mm}(600 \times 600 \mathrm{DPI})$ 